\title{
Electriogram of Associative «Shu-Points» as A Diagnostic Tool for Diseases of the Internal Organs
}

\begin{abstract}
The heart generates the strongest and most extensive rhythmic electromagnetic field in the body. As all cells throughout the body are oriented according to the magnetic vector of the heart, the heart has a powerful influence on everybody process. The activity of immune cells is closely connected to their polarity: when immune cells become depolarized, they are deactivated as a result.

We hypothesize that the heart's electromagnetic signals are distributed throughout the body via the network of acupuncture meridians, similar to the manner in which the heart propels blood throughout the body via blood vessels. The heart's electromagnetic system governs the structure and organization of tissues, as well as the potential - and thus the activity - of all the body's cells, including immune cells. This method of communication is implied in the control of cell proliferation, and its failure in a bodily organ contributes to the cancer process.

Our aim was to determine whether we could monitor the electromagnetic activity in acupuncture points (back SHU points) and record this activity with electrocardiogram or electroencephalogram. In our preliminary trial, we succeeded in recording this electromagnetic activity using electrogram to record activity in back SHU acupuncture points (also known as Associated Points, or Paravertebral Reflex points), but not in an inactive neighboring area (control or "sham" points). We found that the wave shape of electromagnetic activity recorded at SHU points was different in the presence of pathological conditions in a given internal organ, while it remained constant in SHU points representing healthy organs.

In conclusion, our preliminary research offers additional proof for the existence of a sovereign system of biological control over the organization and activity of all bodily tissues, governed by the electromagnetic field generated by the heart and distributed through the network of acupuncture meridians. Our research leads us to believe that the immunomodulating effect of acupuncture results from the restoration of tissue cell structure and cell potential. The stimulation of acupuncture points restores the receptivity of target tissues and immune cells to the heart's electromagnetic signals, thereby restoring the cells' polarity and functional activity.
\end{abstract}

\author{
Letter to Editor \\ Volume 9 Issue 4 - 2017

\section{Nadia Volf $*$} \\ Department of Acupuncture, Harvard Medical School, USA \\ *Corresponding author: Nadia Volf, Department of \\ Acupuncture, Harvard Medical School, Lecturer in the \\ International Structural Acupuncture Course at Harvard \\ Medical School (USA), 9 rue Quentin Bauchart, Paris 75008, \\ France, Tel: (33) 608861094 ; Email : nadia@nadiavolf.com
}

Received: August 15, 2017 | Published: November 22, 2017

\section{Introduction}

Multiple recent studies have highlighted the role of bioelectric signals in large-scale pattern formation in the body's spatial structure and organs, and in organ phylogenesis and ontogenesis, during embryogenesis and regeneration [1-5]. These signals form one layer of physiological control and work in conjunction with biochemical and genetic pathways [6-10]. The bioelectrical state of cells and tissues was shown to regulate their differentiation, migration, and proliferation and plays an important role in the development of cancer [11-25]. Bioelectrical activity has long been implicated in neoplasm, and recent molecular efforts have focused on ion channels as important cancer targets, and ion channel drugs as a promising therapy [26-35]. The nature of these formative biological fields has been defined in modern experimental studies and theoretical constructs as electromagnetic [36,37].
Many papers [38,39] have addressed the influence of electric, magnetic and electromagnetic forces in cells, tissues and the entire organism. Indeed, the activity of all cells in the body fundamentally relates to their biophysical features, which differ under healthy state and pathological conditions, and especially during the cancer process. The activity of a cell's receptors depends on its state of polarity: depolarization is accompanied by deactivation. Specifically, the depolarization of immune cell receptors corresponds to their deactivation and inability to recognize and eliminate pathogenic cells, especially cancer cells [40,41]. The disorganization and depolarization of tissue structures leads to their predisposition to be involved in pathological processes, and to the development of cancer [42].

Polarization has a profound effect on the outcome of oncogenic signaling. For example, chronic activation of oncogenic c-Myc 
results in increased cell proliferation in cells that grow as an unorganized cell population, but has no effect in the same cells when they can form polarized 3D structures. Cellular organization into epithelial architecture maintains structural integrity and homeostasis by suppressing cell proliferation and apoptosis. Organized epithelial architecture is critical for suppression of proliferative oncogenesis, and regulates sensitivity to apoptotic oncogenic function [43].

Thus, the combination of cell polarity disruption and tissue disorganization is a hallmark of advanced epithelial tumors. In normal tissue, simple epithelium comprises a monolayer of individual cells that display distinct apical-basal polarity. Cells are tightly packed and connected to each other by the apical junctional complexes, which separate apical and basolateral membrane domains. By contrast, in high-grade epithelial tumors, cells display a loss of apical-basal polarity and overall tissue disorganization [42].

Cancer cells exhibit different polarity compared to cells in surrounding tissues. Cancerous tumors display altered physicochemical parameters, including the electrochemical equilibrium of the tumor environment. Communication between cancer cells occurs via broadcast. Biophotones influence DNA emissions and structure. In cancer cells, DNA emissions become inconsistent [40].

The body constantly produces an abundance of potentially cancerous cells. The role of the immune system (for example, killer T cells, and especially CD8 cytotoxic cells and macrophages) is to recognize and eliminate potentially cancerous cells. Cancer development is possible only when immune cells lose their ability to identify potentially cancerous cells, due to the desensitization and deactivation of immune cell receptors $[40,41,44]$.

The activity of immune cells and the sensitivity of their receptors is related to their state of polarity: when immune cells become depolarized, their receptors are deactivated. The question remains, what system in the body controls polarity and cell activity, including in immune cells?

Some researchers propose that acupuncture amplifies the biological electromagnetic field, explaining that the enhanced movement of stem cells by a weak electromagnetic field accounts for the results of acupuncture treatment [45].

The ancient tradition of acupuncture has always attributed control of all cell activity to the heart. According to the classic ancient acupuncture text, The Yellow Emperor Classic of Medicine, "The Heart is the Lord and Master of all beings... If then the sovereign radiates, those under him will be at peace; through this the nurturing of life will yield longevity, and that from generation to generation, and the empire will radiate with a great light..." [46].

In addition to the network of nervous and vascular communications, the heart communicates information to the brain and the rest of the body via the electromagnetic field. The heart generates the strongest and most extensive rhythmic electromagnetic field in the body, with a powerful influence on all body processes since all cells are oriented to the magnetic field vector of the heart. The specificity of the heart's electromagnetic activity is well known and is widely used for diagnostic purposes, as in the case of the electrocardiogram (EKG) and magnetocardiogram (MCG).

The heart's magnetic field, 5,000 times stronger than the magnetic field of the brain, can even be detected at a distance using a magnetometer. All of the body's organs and cerebral rhythms are naturally synchronized with the rhythmic activity of the heart, and respond to changes in heart rate, blood pressure, emotional states and respiration. Thus, the heart produces an overall - or "sovereign" - electromagnetic field, to which the entire body is synchronized, and which directs the polarity and thus the activity of all cells, including immune cells [47].

The ancient understanding of the heart's dual facets - the visible and the invisible can be explained as two physiological functions:

a. The "pump", which circulates blood through blood vessels throughout the body; and,

b. The source of electromagnetic emissions broadcast throughout the body, probably through the acupuncture meridian network, in order to maintain cell polarity and physiological activity.

The goal of this study was to explore the propagation of the heart's electromagnetic emissions throughout the body via the acupuncture meridian network and the heart's role in controlling cell polarity and function. We posit that one of the mechanisms of acupuncture action, in particular its immunomodulating effect, is due to the improved sensitivity and activation of immune cells resulting from the restoration of the polarity of their receptors. As the needling of acupuncture points (which have lower electrical resistance compared to surrounding tissue) increases their electrical resistance, it activates the receptivity of immune cells to the heart's electromagnetic signals and thus activates their polarity and functional activity.

\section{Materials and Methods}

Our first goal was as follows: since acupuncture points are frequently described as having distinct electrical properties (increased conductance and elevated electrical potential compared to adjacent non-acupuncture points) [48]; and if we are right that acupuncture meridians carry electromagnetic emissions generated by the heart, then we should be able to monitor the electromagnetic signal at an acupuncture point over an extended time period, as is done with electrocardiograms (EKG) and electroencephalograms (EEG).

Therefore, we attempted to record the electrical signal (electrogram) at the back SHU points and produce a visual graphic of their electric activity, using electroencephalography, where acupuncture needles, placed in acupuncture points, served as electrodes, and were connected to the EEG recorder. The second goal was to check the specificity of this electrical signal recorded from the acupuncture points. For this purpose, we compared the electrogram readings of real acupuncture points with control points (inactive areas or "sham" points). 
Finally, we wanted to determine if the electrogram recording of acupuncture points on the back - the SHU points - might have diagnostic value for the state of different organs, in the same way the EKG is used for heart diagnostics, and the EEG for brain diagnostics. We chose back SHU points for the electrogram tests because they are well known as diagnostic points (points that become tender under palpation when their associated organs are malfunctioning). We compared electrograms of back SHU points in healthy volunteers and in patients with a confirmed pathological condition of an associated organ.

As in electroencephalography, the diagnostic applications were focused on the spectral component of the electrogram, that is, the type of oscillations that can be observed in electrogram signals [49]. Electrogram tests were performed in 18 patients, 2575 years old. Fifteen were healthy subjects ( 10 men, 5 women); 5 patients had gastric ulcer confirmed by endoscopy, and 3 patients had cardiac arrhythmias. Sterile metal acupuncture needles $0,16 \times 25 \mathrm{~mm}$ were used as recording electrodes for the EEG device, as their material was conductive.

\section{The following pairs of symmetrical points were used}

Heart Meridian SHU point (BL15; Xinshu): 1.5 cun lateral to GV11 level with the spinous process of T5. Liver Meridian SHU point (BL18; Ganshu): 1.5cun lateral to GV8 level with the spinous process of T9. Stomach meridian SHU point (BL21; Weishu): 1.5cun lateral to midline level with the spinous process of T12.

Two symmetrical non-points near the left and right BL21 points were tested as controls or "sham" points. Bipolar montage of electrodes was used, each channel representing the difference in voltage between electrodes, connecting the right and left symmetrical points, over a period of 25 minutes. This time period was established empirically: we found that after 20-25 minutes, the acupuncture point's electrogram reading changed: the electrical activity slowly diminished and ultimately stopped, becoming similar to the "sham" (non-active) point reading.

\section{Results}

a. Demonstrable electrical activity was recorded at the SHU points, while no activity was recorded at the "sham" points.

b. The electrogram readings of different SHU points show a different type of waveform (Figure 1).

c. The waveform of the electrogram readings of SHU points was modified when their associated organs were diseased. In patients with confirmed gastric ulcer, the waveform of the electrogram reading of the stomach SHU point (BL 21) was modified, while electrogram readings of other SHU points were similar to those of healthy subjects (Figures 2,3). Similarly, in patients with cardiac arrhythmias, the waveform of the electrogram reading of the heart SHU point (BL 15) was modified, while readings of other SHU points were similar to those of healthy subjects.

d. The abnormal presentation of the electrogram reading of the stomach SHU point (BL21) associated with gastric ulcer disease consisted of a large number of fast, high amplitude discharges (Figure 3). e. The abnormal activity in the electrogram reading of the heart SHU point (BL 15), associated with cardiac arrhythmias, also consisted of a large number of fast, high amplitude discharges (Figure 4).

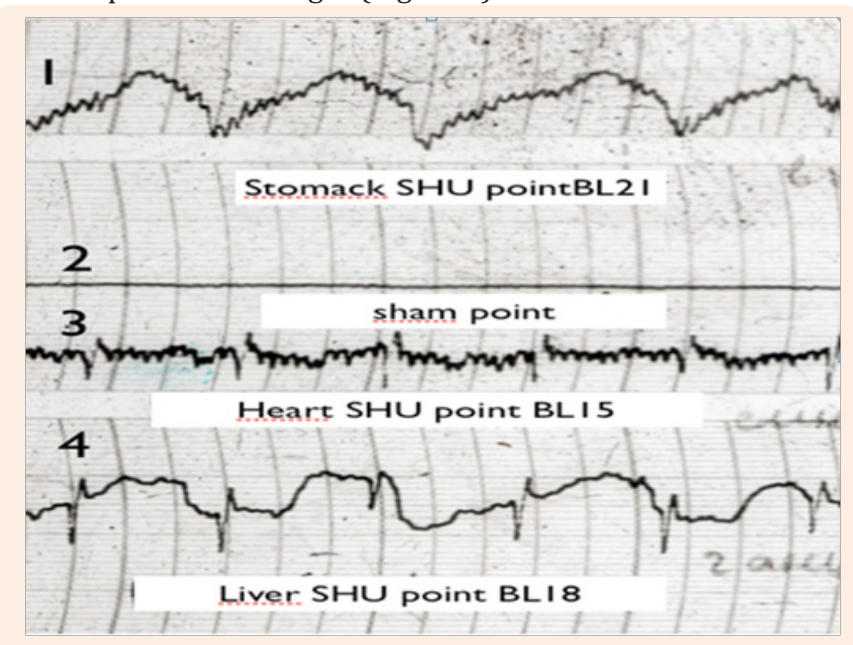

Figure 1: EG Traces of sham (non-active point) and SHU acupuncture points:
1. B121 (Stomack SHU point)
2. Sham point
3. B115 (Heart SHU point)
4. B118 (liver SHU point)

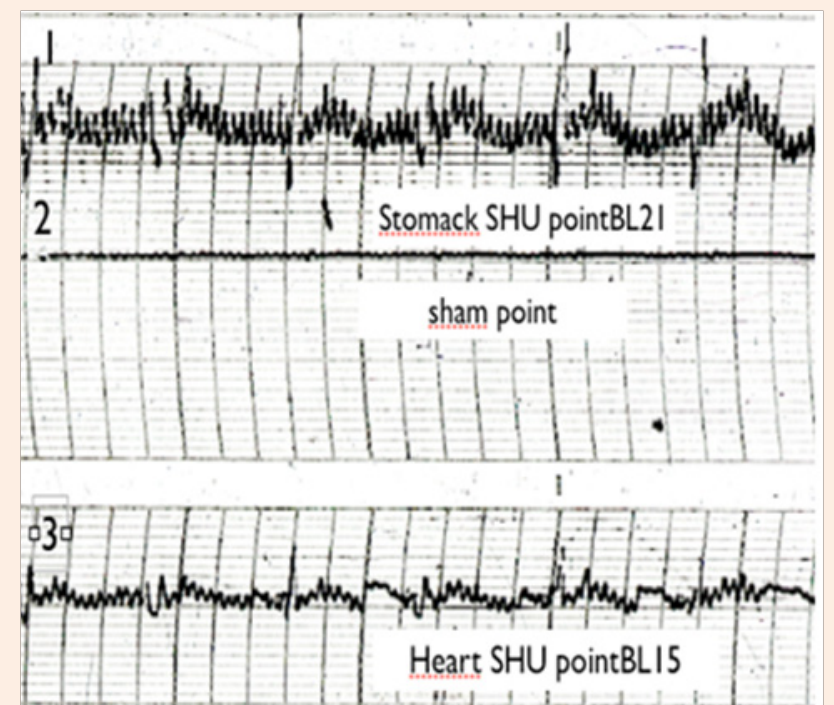

Figure 2: patient with stomack ulcer. EG trace of 1. Stomack SHU point (BL21); 2. Sham(non-active point) and 3. Heart SHU point (B115).

Due to the small number of subjects, acupuncture points tested, and diseases studied, our findings are preliminary. There are many sources of electrical activity in the body, including the heart, respiratory system, and skeletal muscles. We found that the waveform of the electrogram reading of each SHU point was specific and different from that of other SHU points. We observed that substantial changes in the electrographic spectrum of the SHU point electrogram reading occurred when the associated organ was diseased. This might indicate the value of taking an electrogram of SHU points for the early diagnosis of organ disease. 


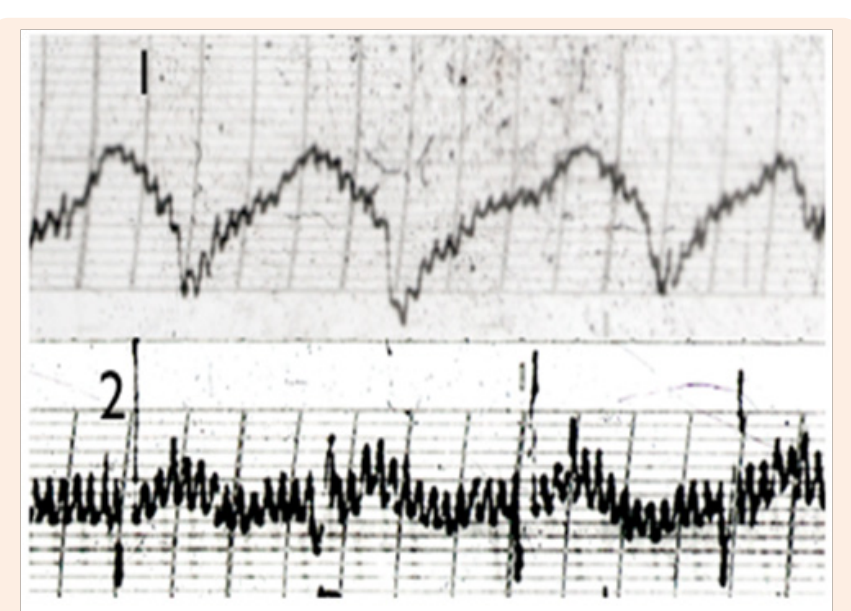

Figure 3: EG trace of Stomack SHU acupuncture points (BL21): 1. Heart SGU point; 2. Patient with confirmed Stomach ulcer.

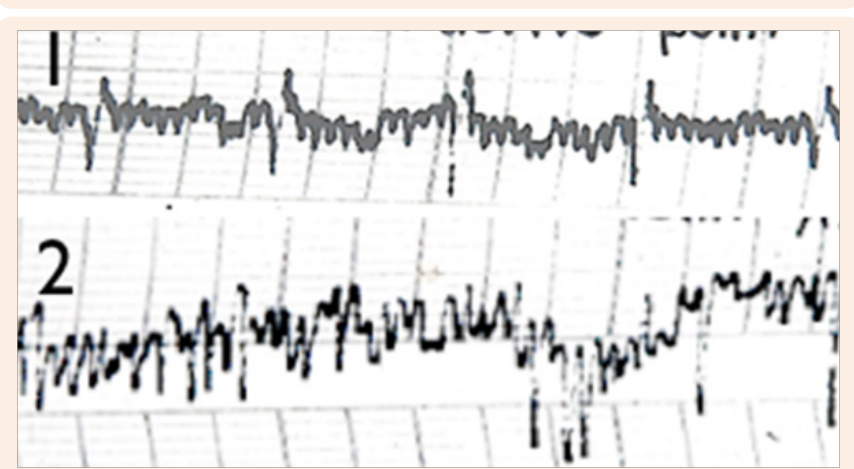

Figure 4: EG trace of Heart SHU acupuncture points (BL 15): 1. Healthy person; 2. Patient with cardiac arrhythmias.

In our studies, SHU points demonstrated continuous electrical activity that was absent in "sham" points. This means that acupuncture points might emit an electromagnetic field, specific to each point, which might be recordable via electrogram. We noted that the duration of electrical activity recorded at SHU points was limited to 20-25 minutes, after which electrical activity disappeared. This phenomenon probably indicates a deactivation of the acupuncture point after 20-25 minutes of stimulation. The acupuncture needles serving as electrodes in this research were placed directly in the acupuncture points, so the needles might have influenced the electrical and physiological activity of the point.

The question remains: does the electrical activity of acupuncture SHU points, as recorded by electrogram in our studies, reflect the heart's electromagnetic field, as distributed through the network of acupuncture meridians and points? Or does it reflect specific spontaneous electrical activity of acupuncture points, which generate their own electrical activity, resulting from ionic current flowing within the specific structures of an acupuncture point? Or does it correspond to the electrical activity of the spinal nervous system, related both to an internal organ and to its associated acupuncture SHU point? We hope to answer these questions in future studies.

\section{Discussion}

Acupuncture without a doubt stimulates immunity, both cellular pattern (different fractions of $\mathrm{NK}$ ) and humoral factors (interleukins, interferons and others immunological substances) [50-55]. Acupuncture's immunomodulating effect is related to the activation of Beta-endorphins in the hypothalamic centers. This activation might employ not only neurological pathways, but may also be related to electromagnetic induction, controlled by the heart, and launched by the stimulation of the acupuncture point.

From a physical standpoint, the intensity of the propagation of electromagnetic emissions depends on two things: the power of the source of these emissions, and the receptivity of tissues. The level of receptivity is conditioned by the level of the tissue's electrical resistance: the lower the resistance, the lower the electromagnetic reception. Areas with lower resistance lose their capacity to receive the heart's electromagnetic emissions which maintains the state of polarity and of functional activity of cell receptors. This leads to the loss of the cell's apical-basal polarity (depolarization) and overall tissue disorganization [42]. This disorganization and depolarization of tissue structures leads to the cell's predisposition to pathological processes and to the development of cancer [42-45].

From a biophysical point of view, the acupuncture points, and especially acupuncture meridians, display lower resistance than other tissues $[48,56,57]$. Acupuncture meridians have the lowest electrical resistance $(7,000-70,000 \mathrm{OHMs})$ compared to the resistance of neighboring tissues $(300,000-2,000,000 \mathrm{OHMs})$. The stronger the pathological process, the lower the electrical resistance in the corresponding acupuncture meridian.

Thus, the needling (or electrical stimulation) of acupuncture points creates a polarizing effect, increasing resistance, and thereby restoring the receptivity of cells to the heart's electromagnetic emissions. "Lowest resistance" in physics refers to tissue with the lowest ability to receive electromagnetic signals. Electromagnetic reception depends on the electrical resistance of tissue: the greater the resistance, the better the reception (or ability of tissues to retain the electromagnetic signal). Acupuncture needling or the electrical stimulation of an acupuncture point leads to an increase in local electrical resistance, and thus the increased capacity of tissue to receive and respond to the heart's electromagnetic emissions.

Acupuncture restores tissue organization, cell polarity and cellular function, which enables immune cells to recognize and eliminate cancer cells. It is well known that acupuncture enhances endogenous anticancer immune function with implications for molecular-level carcinogenic control. Acupuncture improves the function and level of NK cells, activating NK cell receptor expression [50,58,59].

One acupuncture point can be pivotal, though treatment protocols involving synergistic points together will produce better results. This action is realized via the activation of Betaendorphins, especially in the lateral hypothalamus center [51,60-62]. It is interesting that the lateral hypothalamus area, the area of immune control activated by acupuncture, is also 
related to the HACER heart responses, as it has been shown that the heart's electromagnetic field enhances the activity of this same area $[60,61]$, leading to the activation of the biochemical immunomodulating path. Since the immunomodulating action of acupuncture stimulation is realized through the release of Betaendorphins in the same area of the brain, it is conceivable that there is a connection between these two immunomodulation mechanisms. Indeed, it is possible that the needling of acupuncture points, which amplifies the receptivity of immune cells to the heart's electromagnetic emissions, might activate those immune cells' anticancer activity.

In our small-scale preclinical tests, we demonstrated that it is possible to record the electromagnetic activity of the SHU acupuncture points, similar to the way current medical science records heart and brain activity using the EKG and EEG. Electromagnetic activity was detected and recorded exclusively in SHU acupuncture points, and not in inactive neighboring tissues. The recordings were different for different SHU points. Moreover, the shapes of waves recorded at SHU points corresponding to healthy internal organs were different from the waves recorded when a pathological condition was present in a corresponding internal organ.

These results suggest that the electrogram of SHU points might be employed for determining the functional status of internal organs corresponding to specific SHU points in the same way that EKG and EEG testing is used to measure heart and brain function.

In addition, our previous results point to the possibility that acupuncture points respond to the heart's electromagnetic emissions. From those previous results, we might extrapolate that the heart's electromagnetic emissions are distributed, at least partially, via the network of acupuncture points and meridians. According to ancient acupuncture texts (SW Ch 8, 46), "heart radiation" plays a major role in controlling the body's cells. This might be explained as the governing action of the heart's electromagnetic field on the state of polarization and activity of all cells' receptors. Through the network of acupuncture meridians, the "Emperor", or "Invisible Heart", regulates electromagnetic activity throughout the body, including the activity of all cells, activating complementary mechanisms of functioning, thereby accessing the body's enormous potential for healing. This potential exists because, in addition to the body's well-known primary physiological mechanisms, there are also complementary physiological mechanisms which remain inactive under normal conditions. For example, our bodies typically employ only $10 \%$ of available neurons, only $20 \%$ of available blood vessels, and only $10 \%$ of usable DNA. The remainder stays in reserve. Acupuncture has been shown to activate these reserves.

For instance, in experiments in rats, when scientists ligatured the coronary artery - the main source of heart irrigation, the loss of which blood supply leads to myocardial infarction - applying acupuncture to a single point (Pericardium 6) completely protected the rats from developing heart ischemia. The effect of this heart-protective mechanism of acupuncture was due to the activation of the complementary or reserve pathway for irrigation: the stimulation of this acupuncture point activated neighboring arteries - which already existed, but in an inactive state - and these arteries irrigated the heart in place of the coronary artery.

This example demonstrates acupuncture's potential to access and activate the body's "reserve" mechanisms. Interestingly the first point in the heart acupuncture meridian, Ht1, is called "Ultimate Spring", which in Chinese philosophy means "endless possibility". It seems that the ancient chroniclers of acupuncture left modern medicine a tantalizing clue to the amazing potential of acupuncture to open up the body's innate complementary healing mechanisms.

We strongly believe in the existence of a sovereign system of regulation and regeneration of bodily tissues based on electromagnetic signals generated by the heart and distributed via the network of acupuncture meridians. This system controls the organization and maintenance of tissue structures, as well as the state of polarity, and functional activity of all cells, including immune cells. A disturbance in this system that leads to disorganization of cells or tissues in an organ might explain a pathological condition in that organ, since disorganization can lead to disease. Tissue or cell disorganization might occur as a result of faulty genetics or due to an acquired condition that causes tissues to lose their ability to receive and respond appropriately to the heart's electromagnetic instructions. This can occur when local electrical resistance decreases and tissues become unable to receive and/or retain the heart's electromagnetic emissions [6268].

This explains why acupuncture points are known to have lower electrical resistance in the presence of a pathological condition: the lower the electrical resistance, the weaker the response of tissues in a corresponding organ to the electromagnetic communication, which consequently predisposes the organ to disease.

The propagation of the heart's electromagnetic signals through the network of acupuncture meridians would explain the physiological action of acupuncture. The needling of an acupuncture point leads to increased local electrical resistance in the target tissues, resulting in increased receptivity and responsiveness to the heart's electromagnetic control, and restoring organization of tissues through the restored polarity and activity of cell receptors. In addition, acupuncture amplifies the intensity of electromagnetic emissions, improving their ability to regulate tissue organization.

This explains why the strong manipulation of acupuncture needles, including vibration and shaking, intensifies the efficacy of acupuncture: such manipulations increase local electrical resistance and thus receptivity to the heart's electromagnetic signals.

In addition, several studies have shown that acupuncture enhances the flow of stem cells through acupuncture meridians toward a target organ. This increased supply of stem cells replaces the destroyed cells and thus aids in regeneration of tissues. In our opinion, electromagnetic signals generated by the heart regulate the flow of these cells through the acupuncture meridian, and thus control the body's innate potential for regeneration. 


\section{Conclusion}

Our preliminary research offers additional proof for the existence of a sovereign system of control over the organization and function of bodily tissues, the foundation of which is electromagnetic communication generated by the heart, and propagated through the network of acupuncture meridians. The recognized immunomodulating effect of acupuncture is related to the restoration of tissue structure and organization, and cell polarity and function. The needling of acupuncture points activates the receptivity of target tissues and immune cells to the heart's electromagnetic signals and thus restores their polarity and function.

\section{Author Disclosure Statement}

There are no competing financial interests to declare.

\section{Acknowledgment}

None.

\section{References}

1. Adams D, Levin M (2013) Endogenous voltage gradients as mediators of cell-cell communication: strategies for investigating bioelectrical signals during pattern formation. Cell Tissue Res 352(1): 95-122.

2. Adams D (2008) A new tool for tissue engineers: ions as regulators of morphogenesis during development and regeneration. Tissue Eng Part A 14(9): 1461-1468.

3. Chernet B, Levin M (2014) Transmembrane voltage potential of somatic cells controls oncogene-mediated tumorigenesis at longrange. Oncotarget 5(10): 3287-3306.

4. Chernet B, Levin M (2013) Transmembrane voltage potential is an essential cellular parameter for the detection and control of tumor development in a Xenopus model. Dis Model Mech 6(3): 595-607.

5. Tseng A, Levin M (2013) Cracking the bioelectric code: probing endogenous ionic controls of pattern formation. Commun Integr Biol 6(1): 1-8.

6. Levin M (2009) Bioelectric mechanisms in regeneration: unique aspects and future perspectives. Semin Cell Dev Biol 20(5): 543556

7. Levin M (2007) Large-scale biophysics: ion flows and regeneration Trends Cell Biol 17(6): 261-270.

8. Levin M (2013) Reprogramming cells and tissue patterning via bioelectrical pathways: molecular mechanisms and biomedical opportunities. Wiley Interdiscip Rev Syst Biol Med 5(6): 657-676.

9. Pullar C (2011) The physiology of bioelectricity in development, tissue regeneration, and cancer. Biological effects of electromagnetics series. CRC Press, Boca Raton, Florida.

10. Chernet B, Levin M (2013) Endogenous voltage potentials and the microenvironment: bioelectric signals that reveal, induce and normalize cancer. J Clin Exp Oncol S1.

11. Levin M (2014) Endogenous bioelectrical networks store non-genetic patterning information during development and regeneration. J Physiol 592(11): 2295-2305.
12. Pai V, Martyniuk C, Echeverri K, Sundelacruz S, Kaplan D, et al. (2015) Genome-wide analysis reveals conserved transcriptional responses downstream of resting potential change in Xenopus embryos, axolotl regeneration, and human mesenchymal cell differentiation. Regeneration Regeneration (Oxf) 3(1): 3-25.

13. Rao V, Perez-Neut M, Kaja S, Gentile S (2015) Voltage-gated ion channels in cancer cell proliferation. Cancers (Basel) 7(2): 849875 .

14. Sundelacruz S, Levin M, Kaplan D (2009) Role of membrane potential in the regulation of cell proliferation and differentiation. Stem Cell Rev 5(3): 231-246.

15. Blackiston D, McLaughlin K, Levin M (2009) Bioelectric controls of cell proliferation: ion channels, membrane voltage and the cell cycle. Cell Cycle 8(21): 3519-3528.

16. Urrego D, Tomczak A, Zahed F, Stuhmer W, Pardo L (2014) Potassium channels in cell cycle and cell proliferation. Philos Trans R Soc Lond B Biol Sci 369(1638): 20130094.

17. Becchetti A (2011) Ion channels and transporters in cancer; ion channels and cell proliferation in cancer. Am J Physiol Cell Physiol 301(2): C255-C265.

18. Kasemeier-Kulesa J, Teddy J, Postovit L, Seftor E, Seftor R, et al. (2008) Reprogramming multipotent tumor cells with the embryonic neural crest microenvironment. Dev Dyn 237(10): 2657-2666.

19. Hess A, Margaryan N, Seftor E, Hendrix M (2007) Deciphering the signaling events that promote melanoma tumor cell vasculogenic mimicry and their link to embryonic vasculogenesis: role of the Eph receptors. Dev Dyn 236(12): 3283-3296.

20. Hendrix M, Seftor E, Seftor R, Kasemeier-Kulesa J, Kulesa P, et al. (2007) Reprogramming metastatic tumor cells with embryonic microenvironments. Nat Rev Cancer 7(4): 246-255.

21. Hendrix M, Seftor E, Hess A, Seftor R (2003) Vasculogenic mimicry and tumor-cell plasticity: lessons from melanoma. Nat Rev Cancer 3(6): 411-421.

22. Tarin (2012) Clinical and biological implications of the tumor microenvironment. Cancer Microenviron 5(2): 95-112.

23. Maffini M, Calabro J, Soto A, Sonnenschein C (2005) Stromal regulation of neoplastic development: age-dependent normalization of neoplastic mammary cells by mammary stroma. Am J Pathol 167(5): 1405-1410.

24. Binggeli R, Weinstein R (1986) Membrane potentials and sodium channels: hypotheses for growth regulation and cancer formation based on changes in sodium channels and gap junctions. J Theor Biol 123(4): 377-401.

25. Burr H, Strong L, Smith G (1938) Bioelectric correlates of methylcolantherene-induced tumors in mice. Yale J Biol Med 10(6): 539-544.

26. Yang M, Brackenbury W (2013) Membrane potential and cancer progression. Front Physiol 4:185

27. Chen J, Luan Y, Yu R, Zhang Z, Zhang J, et al. (2014) Transient receptor potential (TRP) channels, promising potential diagnostic and therapeutic tools for cancer. Biosci Trends 8(1): 1-10.

28. Chernet B, Adams D, Lobikin M, Levin M (2016) Use of genetically encoded, light-gated ion translocators to control tumorigenesis. Oncotarget 7(15): 19575-19588. 
29. Lang F, Stournaras C (2014) Ion channels in cancer: future perspectives and clinical potential. Philosophical Transactions of the Royal Society of London Series B, Biological Sciences 369(1638): 20130108.

30. Onkal R, Djamgoz M (2009) Molecular pharmacology of voltagegated sodium channel expression in metastatic disease: clinical potential of neonatal Nav1.5 in breast cancer. Eur J Pharmacol 625(1-3): 206-219.

31. Fraser S, Pardo L (2008) Ion channels: functional expression and therapeutic potential in cancer. Colloquium on Ion Channels and Cancer. EMBO Rep 9(6): 512-515.

32. Brackenbury W, Isom L (2008) Voltage-gated Na+ channels potential for beta subunits as therapeutic targets. Expert opinion on therapeutic targets 12(9): 1191-1203.

33. Huang X, He Y, Dubuc A, Hashizume R, Zhang W, et al. (2015) EAG2 potassium channel with evolutionarily conserved function as a brain tumor target. Nat Neurosci 18(9): 1236-1246.

34. Djamgoz M, Coombes R, Schwab A (2014) Ion transport and cancer: from initiation to metastasis. Philos Trans R Soc Lond B Biol Sci 369(1638): 20130092

35. Arcangeli A, Pillozzi S, Becchetti A (2012) Targeting ion channels in leukemias: a new challenge for treatment. Curr Med Chem 19(5): 683-696.

36. Arcangeli A, Crociani O, Lastraioli E, Masi A, Pillozzi S, et al. (2009) Targeting ion channels in cancer: a novel frontier in antineoplastic therapy. Curr Med Chem 16(1): 66-93.

37. Frede J, Fraser S, Oskay-Ozcelik G, Hong Y, Ioana Braicu E, et al. (2013) Ovarian cancer: ion channel and aquaporin expression as novel targets of clinical potential. Eur J Cancer 49(10): 2331-2344.

38. Kaznacheev V, Mikhailova L, Kartashov N (1980) Distant intercellular electro-magnetic interaction between two tissue cultures. Bull Exp Biol Med 89(3): 345-348.

39. Yung K (2004) A birdcage model for the Chinese Meridian System: part I. A channel as a transmission line. Am J Chin Med 32(5): 815828.

40. Adey W (1993) Biological effects of electromagnetic fields. J Cell Biochem 51(4): 410-416.

41. Emelyanov A, Kiryanova V (2015) Photomodulation of proliferation and differentiation of stem cells by the visible and infrared light. Photomed Laser Surg 33(3): 164-174.

42. Galon J, Costes A, Sanchez-Cabo F, Kirilovsky A, Mlecnik B, et al. (2006) Type, density, and location of immune cells within human colorectal tumors predict clinical outcome. Science 313(5795): 1960-1964.

43. Mlecnik B, Bindea G, Pages F, Galon J (2011) Tumor immunosurveillance in human cancers. Cancer Metastasis Rev 30(1): 5-12.

44. Bindea G, Mlecnik B, Fridman W, Pages F, Galon J (2010) Natural immunity to cancer in humans. Curr Opin Immunol 22(2): 215222

45. Lee M, Vasioukhin V (2008) Cell polarity and cancer - cell and tissue polarity as a non-canonical tumor suppressor. J Cell Sci 121(8): 1141-1150
46. Partanen J, Nieminen A, Makela T, Klefstrom J (2007) Suppression of oncogenic properties of c-Myc by LKB1-controlled epithelial organization. Proc Natl Acad Sci USA 104(37): 14694-14699.

47. Bindea G, Mlecnik B, Fridman W, Pages F, Galon J (2010) Natural immunity to cancer in humans. Curr Opin Immunol 22(2): 215222.

48. Emelyanov A, Borisova M, Kiryanova V (2016) Model acupuncture point: bone marrow-derived stromal stem cells are moved by a weak electromagnetic field. World J Stem Cells 8(10): 342-354

49. Huang Di N (2011) An annotated translation of Huang Di's inner classic - basic questions. Paul U. Unschuld and Hermann Tessenow in Collaboration with Zheng Jinsheng; University of California Press, Berkeley, Los Angeles, USA, pp.1560.

50. McCraty R, Atkinson M, Tomasino D (2001) Exploring the role of the heart in human performance. HeartMath Research Center Institute of HeartMath, Boulder Creek, USA.

51. Ahn A, Martinsen $\varnothing$ (2007) Electrical characterization of acupuncture points: technical issues and challenges. J Altern Complement Med 13(8): 817-824.

52. Niedermeyer E, da Silva F (2004) Electroencephalography: basic principles, clinical applications, and related fields. Lippincot Williams \& Wilkins, USA.

53. Yamaguchi N, Takahashi T, Sakura M, Sugita T, Uchikawa K, et al. (2007) Acupuncture regulates leukocyte subpopulations in human peripheral blood. Evid Based Complement Alternat Med 4(4): $447-$ 453.

54. Johnston M, Sánches E, Vujanovic N, Li W (2011) Acupuncture may stimulate anti- cancer immunity via activation of natural killer cells. Evid Based Complement Alternat Med 2011: 481625.

55. Ye F, Liu D, Wang S, Xu L (2007) Effects of electro-acupuncture on T cell subpopulations, NK activity, humoral immunity and leukocyte count in patients undergoing chemotherapy. J Tradit Chin Med 27(1): 19-21.

56. Tlaskalová-Hogenová $H$, Stepánková R, Hudcovic T, Tucková L, Cukrowska B, et al. (2004)Commensal bacteria (normal microflora), mucosal immunity and chronic inflammatory and autoimmune diseases. Immunol Lett 93(2-3): 97-108.

57. Lu YM, Zhang H, Tang CZ (2011) Effects of electroacupuncture on IL-2-IFN-NKC immunity immunoloregulation net and IL-2 receptor in rats with exercise stress. Zhongguo Zhen Jiu 31(9): 817-820.

58. Liu Y, Liu X, Bai S, Mu LL, Kong QF, et al. (2010) The effect of electroacupuncture on $\mathrm{T}$ cell responses in rats with experimental autoimmune encephalitis. Neuroimmunol 220(1-2): 25-33.

59. Stockert K, Schneider B, Porenta G, Rath R, Nissel H, et al. (2007) Medicine. Pediatr Allergy Immunol 18(2): 160-166.

60. Andrew C, Ahn A, Colbert A, Anderson B, Martinsen O, et al. (2008) Electrical properties of acupuncture points and meridians: systematic review. Bioelectromagnetics 29(4): 245-256.

61. Kirschvink J (1997) Magnetoreception: homing in on vertebrates Nature 390(6658): 339-340.

62. Biron C, Nguyen K, Pien G, Cousens L, Salazar-Mather T (1999) Natural killer cells in antiviral defense: function and regulation by innate cytokines. Annu Rev Immunol 17: 189-220. 
63. Hisamitsu T, Kasahara T, Umezawa T, Ishino T, Hisamitsu N, et al (2002) The effect of acupuncture on natural killer cell activity. International Congress Series 1238 (2002): 125-131.

64. Choi G, Oh S, Han JB, Bae HS, Cho YW, et al. (2002) Modulation of natural killer cell activity affected by electroacupuncture through lateral hypothalamic area in rats. Neurosci Lett 329(1): 1-4.

65. Ezzo J, Richardson M, Vickers A, Allen C, Dibble SL, et al. (2006) Acupuncture-point stimulation for chemotherapy-induced nausea or vomiting. Cochrane Database Syst Rev 2: CD002285.
66. Hui K, Hui E, Johnston M (2006) Theatre potential of a personcentered approach in caring for patients with cancer: a perspective from the UCLA Center for East-West Medicine. Integr Cancer Ther 5(1): 56-62.

67. Dimicco J, Sarkar S, Zaretskaia M, Zaretsky D (2006) Stress-induced cardiac stimulation and fever: common hypothalamic origins and brainstem mechanisms. Auton Neurosci 126-127: 106-119.

68. De Menezes R, Zaretsky D (2009) Cardiovascular and thermal responses evoked from the periaqueductal grey require neuronal activity in the hypothalamus. J Physiol 587(Pt 6): 1201-1215. 